\title{
Органы местного самоуправления в системе публичной власти: опыт Польши и России
}

\begin{abstract}
Резюме: В статье рассматриваются разноаспектные проблемы организации и деятельности органов местного самоуправления в системе органов публичной власти. Проанализированы основные положения теорий местного самоуправления, оказавших влияние на формирование законодательства об органах местного самоуправления в Польше и России. С учетом обобщения научных взглядов Т. Биго в сопоставительном ключе приведены положения из польского опыта и российской практики о правовых формах публично-правовых образований в сфере государственного и муниципального управления. Приведены конституционно-правовые новеллы о единстве системы органов публичной власти, воплощенные в российском учредительном акте новейшего времени. На основе компаративистских аналогий опыта организации и взаимодействия государственного и муниципального уровней публичной власти в Польше и России обозначены наиболее значимые направления и формы их правовой регламентации.
\end{abstract}

Ключевые слова: публичная власть, система публичной власти, местное самоуправление, муниципальное образование, органы местного самоуправления, теории местного самоуправления, законодательство.

Местное самоуправление - основа демократии, развитие местного самоуправления - залог зрелого гражданского общества и правового государства. В современных условиях существования государства и общества положения, выработанныенаучноймысльюоместномсамоуправлениикакимманентном свойстве и признаке публичной власти, воспринимаются как непреложные аксиомы.

В науке конституционного и административного права местное самоуправление, так же как и власть государственная, признается видом публичной власти. Существующие теории местного самоуправления, эволюционируя на 
протяжении двух последних столетий, сводятся к необходимости его признания уровнем власти в масштабе государства. Принципиальные различия проявляются во взглядах на отношения местного самоуправления и государственной власти, отчего производны вопросы организации и взаимодействия данных видов органов публичной власти: уровень государственного управлени я - государственная теория; самостоятельный уровень управления общественная теория; взаимодействие при выполнении на местном уровне и государственных дел - общественно-государственная теория.

Практика организации власти на местном уровне в советский период российской государственности и в ряде стран «народной демократии», к каким относилась Польская Народная Республика, основывалась на постулатах, выработанных государственной теорией.

Польский ученый административист Тадеуш Биго хорошо известен в российских академических кругах. Идеи, высказанные им в середине $\mathrm{XX}$ века, явились заметным вкладом в развитие юридической научной мысли о местном самоуправлении. Т. Биго - яркий представитель государственной теории местного самоуправления. Вместе со своими современниками Е. Панейко, М. Ярошиньским им развивалась идея о примате возникновения государства, внутри которого наряду с государственным затем возникло самоуправление местной общины - гмины (от нем. gemeinde). В российской интерпретации польским аналогом гмины можно считать муниципальное образование, муниципальный район, т. е. так же, как и в Польше, наименьшую административно-территориальную единицу.

Современное представление о самоуправлении в Польше и в России, как известно, формировалось, начиная с XIX века, под влиянием немецкого учения и может быть по-русски определено как «независимое управление», разумеется, подразумевается независимость от государства на местном уровне. В доктрине государственного происхождения местного самоуправления оно создается самим государством, представляется результатом его деятельности, т. е. рассматривается не только уровнем, но и формой осуществления управления государством. Преимущество такого подхода, как, в частности, об этом также писал в своих работах Т. Биго ${ }^{1}$, в том, что гмина не противопоставляется государству. При таком подходе проявляется органика взаимодействия государства в целом и гмины как обособленной части, поскольку она занимается по сути своей децентрализованным управлением в пределах территориальной единицы на местном уровне, обеспечивая правопорядок, основанный на положениях закона, которым наделяется властными полномочиями. Отсюда государство определяет предметную сферу

1 T. Bigo, Zwiąki publiczno-prawne w świetle ustawodawstwa polskiego, Warszawa 1990; idem, Prawo administracyjne. Część ogólna (stenogram wykładów uniwersyteckich), Lwów 1932; idem, Z ustrojowych zagadnień samorządu, Lwów 1933.

Prawo 333, 2021

(C) for this edition by CNS 
задач и функций органов местного самоуправления, оставляя себе функции обороны, внешней политики, общегосударственных финансов и все то, что не может осуществить гмина.

Согласно государственной теории компетенция границ гмины и ее властных пределов при осуществлении управления на своем уровне определяются самим государством. Ввиду этого особую значимость приобретают формы государственного контроля за выполнением органами местного самоуправления возложенных на них управленческих задач и функций. При этом среди приверженцев данной теории, в разработку которой заметный вклад внес Т. Биго, имелись и различия во взглядах на такие аспекты, как например, правосубъектность гмины. Так, Ежи Панейко считал, что правосубъектность гмины может составить сущность самоуправления только в рамках последнего и при условии существования отдельных от государства субъектов, обладающих собственными прерогативами ${ }^{2}$. В отличие от него, Т. Биго придерживался позиции, согласно которой самоуправление представляется группой лиц, наделенных правосубъектностью. В сущности, речь идет о распространении понятия юридического лица публичного права.

Одно из главных направлений в научном наследии профессора Т. Биго исследование публично-правовых корпораций, которые рассматривались им как организации, действующие на основе обязательного членства, приобретая права юридического лица публичного права. В СССР был хорошо известен его фундаментальный труд - докторская диссертация «Публично-правовые корпорации в польском законодательстве» (Варшава, 1928 г.) $)^{3}$. Наиболее значимые положения, высказанные ученым в тот период строительства польской государственности, оказали свое влияние на развитие в последующем административно-правовой мысли о правовом регулировании и судебных решениях по отношению к деятельности публично-правовых корпораций, их законодательному закреплению, основным принципам организации и функционирования, взаимодействия с органами государственной власти, а также рассмотрению коллизий, споров и разногласий путем административного и судебного разбирательств.

Разумеется, наука и следующий за ней закон не стоят на месте, отражая в своем поступательном развитии реалии изменчивой практики. В наше время, когда в первой четверти XXI века возобладали процессы глобализации, перед государствами стоят задачи приведения в соответствие новым вызовам институтов и механизмов управления национального уровня на основе базовых принципов интеграции в мировое сообщество при сохранении преимуществ собственной конкурентоспособности. В подобном контексте сопоставительный анализ института самоуправления в странах с близкими

\footnotetext{
2 J. Panejko, Geneza i podstawy samorzadu europejskiego, Wilno 1934.

3 T. Bigo, Zwiąki publiczno-prawne...
} 
условиями государственного строительства и положенной в его основание правовой доктрины представляет актуальный интерес. Республика Польша, где проведены многоступенчатые административно-политические реформы, так же как и в Российской Федерации, при всех, несомненно, наличествующих различиях, имеются и свои аспективно перекликающиеся особенности.

Опыт «польского пути» в направлении поиска эффективной модели организации публичной власти местного уровня представляется поучительным для российских аналогов в условиях крайне сложного и противоречиво идущего процесса включения органов местного самоуправления в единую систему публичной власти. Территориальные начала самоуправления исходят не только из необходимости обеспечить устойчивое развитие местных сообществ, они также носят политико-правовой характер, поскольку неразрывно связаны с процессом противоборства централизации и децентрализации, деволюции власти.

По Конституции Польши местному самоуправлению в его административно-территориальных границах отводится решение публичных задач, не закрепленных конституционными или законодательными нормами за органами иных публичных властей. На конституционном уровне для местных органов публичной власти определен весь круг полномочий, не установленных для органов иных видов публичной власти - государственной. На основе Конституции органы местного самоуправления в пределах законодательно очерченных для них полномочий издают акты местного права, имеющие юридическую силу и действующие на данной территории. Собственные задачи местного самоуправления определены польским законодательством как публичные задачи, решение которых призвано служить удовлетворению потребностей населения самоуправленческого сообщества. Реализация публичных задач здесь обеспечивается посредством участия в «публичных доходах», под которыми понимаются все виды доходов, поступающих в государственные или местные бюджеты ${ }^{4}$.

С принятием поправок 2020 года в Конституцию РФ воплощается идея о включении местного самоуправления в единую систему публичной власти. Местное самоуправление осуществляется в муниципальных образованиях, виды которых устанавливаются федеральным законом. Структура органов местного самоуправления определяется населением самостоятельно, но в соответствии с общими принципами организации, устанавливаемыми федеральным законом. При этом органы государственной власти могут участвовать в формировании органов местного самоуправления, назначать на должности и освобождать от должностей должностных лиц местного самоуправления также в соответствии с правами, предоставленными федеральным законом 5 .

\footnotetext{
4 Конституция Республики Польша от 2 апреля 1997 года.

5 Конституция Российской Федерации 12 декабря 1993 года.
} 
Если до принятия в 2020 году поправки в ч. 1 ст. 110 Конституции РФ исполнительную власть осуществляло Правительство РФ, то после принятия поправки исполнительная власть осуществляется под общим руководством Президента РФ. К тому же Правительство РФ, согласно ч. 3 ст. 110, не руководит деятельностью всех федеральных органов исполнительной власти, так как в эту систему входят и те федеральные органы исполнительной власти, которыми руководит непосредственно Президент РФ. Прежде всего, это так называемые органы административно-политического блока, где превалируют «силовые» ведомства в области обороны, безопасности, внутренних дел, юстиции, а также в области иностранных дел. Тем самым, если раньше возникали вопросы об отнесении института президентства к той или иной ветви власти, то с недавних пор он однозначно включен в систему исполнительной власти, сохраняя влияние на законодательную и судебную власти.

В соответствии с ч. 2 ст. 80 Конституции РФ Президент РФ призван обеспечивать согласованное функционирование и взаимодействие органов, входящих в единую систему публичной власти. Исходя из толкования данного положения, можно определенно усматривать усиление президентской власти на все ветви государственной власти, построение которых зиждется на принципе разделения властей. С целью обеспечения согласованного функционирования и взаимодействия органов публичной власти, в соответствии с вновь установленной прерогативой п. «е» ч. 5 ст. 83, Президент РФ формирует Государственный Совет, статус которого определяется специальным федеральным законом об этом органе. При этом организация публичной власти относится к ведению Российской Федерации, т. е. включая и местное самоуправление, но это не касается органов местного самоуправления, которые формируются населением муниципального образования самостоятельно. Данное распределение предмета правового регулирования проистекает из фундаментального положения об основах конституционного строя, в соответствии с которым органы местного самоуправления не входят в систему органов государственной власти.

Как гласит ч. 3 ст. 132 Конституции РФ, органы местного самоуправления и органы государственной власти входят в единую систему публичной власти в Российской Федерации и осуществляют взаимодействие для наиболее эффективного решения задач в интересах населения, проживающего на соответствующей территории. Особенности публичной власти на территориях городов федерального значения, административных центров (столиц) субъектов Российской Федерации и на других территориях могут устанавливаться федеральным законом. Нормой ст. 133 введено понятие публичных функций, под которыми, исходя из буквального толкования, следует понимать совместное взаимодействие органов государственной власти и органов местного самоуправления. 
Единство системы органов публичной власти представляет собой сложное многокомпонентное свойство, характеризующее совместимость компетенций разного уровня и предметов деятельности при осуществлении властных функций и полномочий, а также выражает особый характер существующих между ними отношений, обуславливающих самостоятельность в системной целостности. Взаимоотношения государственной власти и местного самоуправления оказывают существенно значимое влияние на характер единства власти. На каждом из названных уровней государственной власти ее единство закрепляется в конституционных актах, а на уровне местного самоуправления также и в муниципально-статутных актах учредительной значимости. При этом данное единство обеспечивается в специфических формах и процедурах, например, в таких как делегирование полномочий от органа одного вида публичной власти к другому, заключение договоров и соглашений, создание государственно-муниципальных организаций и т. п.

На конституционном уровне закрепляется новое для российского законодательства понятие «публичные полномочия, имеющие государственное значение», т. е. значимые для государства. Содержательно оно шире понятия «государственные полномочия», поскольку наряду с собственно государственными, включает в себя и те полномочия, которые не являются государственными, но имеют государственное значение. Здесь подразумеваются и те полномочия, которые а) делегированы органам местного самоуправления государственными органами через механизм передачи на основе заключаемых между ними соглашений либо б) являются муниципальными, которые признаются государственно значимыми. В этой связи возникает необходимость толкования вновь закрепляемого конституционной нормой понятия.

С понятиями «публичная власть», «публичное управление» неразрывно понятие «публичная служба», как институт обеспечения их осуществления и реализации. Публичная служба представляет собой в общепринятом понимании международную (в органах международных организаций), государственную (федеральную и субфедеральную - региональную) и муниципальную службу. Административно-правовые аспекты публичной службы - ее системы, единства принципов и взаимосвязи, общего правового регулирования видов службы и т. д., остаются актуальными для науки и практики. В доктрине государственной службы, воплощенной российским законодательством о государственной и муниципальной службе, служба на государственных и муниципальных должностях, а также на должностях в государственных и муниципальных учреждениях с публичными функциями, не признается служебной деятельностью. Согласно доктрине, положенной в основу действующего законодательства о государственной службе, оно не распространяется на деятельность лиц, осуществляющих непосредственно 
властные полномочия органа власти (президент, сенатор, судья, мэр и т. п.), а также оно не распространяется на тех, кто работает в государственных организациях, учреждениях, предприятиях (учителей, врачей, сотрудников бюджетных фондов и т. п.). В настоящих условиях встает задача приведения законодательства о государственной службе, которое имеет двухуровневую структуру, а также законодательства о муниципальной службе, в соответствие с конституционным закреплением принципа единства системы публичной службы.

Детализацию конституционных норм антикоррупционной направленности отразило включение в предметы ведения Российской Федерации полномочий по установлению ограничений для замещения государственных и муниципальных должностей, должностей государственной и муниципальной службы, в том числе связанных с иностранным гражданством. Подобные ограничения устанавливаются текущим федеральным законодательством в полном соответствии с ч. 2 статьи 55 Конституции РФ. Весьма обширны административно-правовые ограничения, установленные специальными федеральными законами о государственной гражданской службе, которые распространяются и на муниципальную службу на основе принципа взаимосвязи обоих видов службы, а также на иных лиц, осуществляющих публичные полномочия. Кроме того, административно-правовые ограничения установлены антикоррупционным законодательством, состоящем их ряда федеральных актов, включающих ряд федеральных законов, прежде всего Федеральный закон «О противодействии коррупции», Федеральный закон «О контроле за соответствием расходов лиц, замещающих государственные должности, и иных лиц их доходам», Федеральный закон «О запрете отдельным категориям лиц открывать и иметь счета (вклады), хранить наличные денежные средства и ценности в иностранных банках, расположенных за пределами территории Российской Федерации, владеть и (или) пользоваться иностранными финансовыми инструментами» и других актов, в том числе издаваемых Президентом РФ, Правительством РФ и иными государственными органами.

Мировой опыт и муниципально-правовая практика, сопряженная с практикой государственного управления, открывают широкий простор для изучения вариантов организации местного самоуправления во всем многообразии его теоретико-правового описания. Имея собственную национальную специфику, они обладают и некоторым однородным единством свойств, обобщаемых группировкой систем (моделей), в рамках которых сформировано местное самоуправление как вид публичной власти. В отличие от англосаксонской модели, получившей распространение в англоязычных странах (в Британии, США, Канаде, Австралии, Индии, Новой Зеландии), в России и Польше, как и во Франции, Италии, Бельгии, Турции и ряде других стран, применена романская (континентальная) модель. Существует и так называе- 
мая иберийская модель, сложившаяся в таких странах, как например: Португалия, Аргентина, Бразилия, Мексика. При всех различиях трех моделей в условиях глобализующегося мира и все более заметного взаимопроникновения различных правовых систем, набирающих силу процессов универсализации принципов демократического управления делами государства и общества наблюдаются тенденции сближения и самих систем (моделей) местного самоуправления.

В настоящее время наличие эффективного местного самоуправления, отвечающего международным стандартам, рассматривается как важнейший показатель демократизма существующего государственного режима. Органы местного самоуправления, являясь определенным противовесом центральной власти, централизованной системе государственного управления, возникли и развивались как наиболее приближенные к населению, к его жизненным нуждам, будучи призваны отвечать потребностям решения вопросов жизнедеятельности местного сообщества. Волна децентрализации, прокатившаяся практически по всем западноевропейским странам с конца 1970-х до начала 1980-х годов, заставила центральные власти почти повсеместно осуществить перераспределение полномочий и ответственности между различными уровнями власти, расширив сферу компетенции нижних уровней, т. е. органов местного самоуправления.

Основным международно-правовым актом, регламентирующим муниципальные отношения в большинстве европейских стран, является Европейская хартия местного самоуправления, открытая для подписания с 15 октября 1985 года. В этом документе особо подчеркивается необходимость создания специальных органов, избираемых всеобщим голосованием, ответственных за управление общественными делами. При этом указанная Хартия признает подотчетность исполнительных органов избираемым (представительным) органам местного самоуправления. Одна из основных целей Европейской хартии местного самоуправления заключается в восполнении общеевропейских нормативов определения и защиты прав местных органов власти. Государства-участники Хартии обязуются закрепить и применять на практике правовые нормы, гарантирующие политическую, административную и финансовую независимость местных властей. Вместе с тем, это не означает, что все государства обязаны скопировать положения Хартии. Однако она оказала заметное влияние на формирование как польского, так и российского законодательства.

В результате проведенной реформы в начале 2000-х годов, что можно связать с принятием Федерального закона «Об общих принципах организации местного самоуправления», в Российской Федерации сформировалась и стабилизировалась национальная модель местного самоуправления. Стоит заметить, что Россия всегда тяготела к имплементации зарубежных аналогов в национальном праве. Эта особенность коснулась и заимствований инсти- 
тута местного самоуправления. Вышеуказанный закон сочетает как положительные черты отечественной трансформации системы публичной власти местного уровня, ее организации и функционирования, так и аналогов, заимствованных с учетом передового адаптивного опыта зарубежных государств.

В основу ныне действующего в Российской Федерации закона, регулирующего сферу местного самоуправления, положена немецкая модель, проявляющая вариативное сочетание форм осуществления местной власти при значительном влиянии на нее государственного управления. Наряду с этим местное самоуправление было создано в двухуровневом измерении с четко закрепленной компетенцией каждого из обоих уровней, как в германской и англосаксонской моделях. А также законодательно в России впервые была закреплена такая организационная форма, как «Совет - управляющий», распространенная в США. Кроме того, из французской модели заимствован институт мэра как градоначальника, возглавляющего систему государственного и муниципального управления в части ее исполнительно-распорядительных полномочий.

Однако нельзя игнорировать тот факт, что извечная проблема взаимоотношений между центральными и местными органами власти до сих пор полностью не решена ни в одной стране Европы. Об этом свидетельствует и то, что по меньшей мере двухвековая дискуссия между апологетами государственной и общественной теорий не прекращается. Само по себе данное обстоятельство побуждает ученых разных стран искать пути решения проблемы взаимодействия всех уровней публичной власти. Именно противоречивое становление взаимоотношений между государственной и муниципальной властью привело на практике к развитию различных систем (моделей) местного самоуправления. В настоящее время в Российской Федерации, как уже отмечалось, согласно конституционным поправкам, предпринята попытка решения данного вопроса путем создания единой системы органов публичной власти.

Одним из центральных вопросов, интересовавших профессора Т. Биго, было то, как органы государственной власти используют публично-правовые корпорации и сотрудничают с ними при выполнении своих управленческих функций в публично-правовой сфере. Пожалуй, эти вопросы находят отражение в совместном создании государственно-муниципальных организаций, выполняющих общие задачи и функции. Договора и соглашения в обязательном порядке должны определять источники финансирования совместных мероприятий и иных актов взаимодействия государственных и муниципальных органов власти и устанавливать обязанности сторон по обеспечению этого взаимодействия материально-финансовыми ресурсами.

При осуществлении совместной деятельности путем создания государственно-муниципальных организаций органы государственной и муниципальной власти, находящиеся в единстве публичной власти, могут создавать наблюдательные советы и иные централизованные структуры, компетенция 
которых определяется уставами этих организаций. С точки зрения целей создания государственные и муниципальные организации могут быть коммерческими и некоммерческими. Коммерческие могут осуществлять свою деятельность в организационно-правовой форме унитарного предприятия на праве оперативного управления и хозяйственного ведения. По гражданскому законодательству РФ унитарными предприятиями признаются коммерческие организации, не наделенные правом собственности на закрепленное за ними имущество собственника.

Государственные и муниципальные некоммерческие организации могут осуществлять свою деятельность в большем разнообразии различных организационно-правовых форм. К их числу могут относиться ассоциации (союзы) экономического взаимодействия субъектов Российской Федерации, советы муниципальных образований субъектов Российской Федерации, бюджетные или казенные учреждения, государственные корпорации. Так, например, ассоциациями (союзами) экономического взаимодействия субъектов Российской Федерации признаются некоммерческие организации, учредителями которых являются органы государственной власти субъектов Российской Федерации и которые создаются на добровольной основе в целях межрегиональной интеграции и социально-экономического развития субъектов Российской Федерации. Советы муниципальных образований субъектов Российской Федерации, которые создаются в каждом субъекте Российской Федерации, организуют свою деятельность на основе требований Федерального закона «О некоммерческих организациях».

Взаимодействие органов государственной власти и органов местного самоуправления по вопросам, представляющим взаимный интерес или имеющим значение для населения конкретной местности как административно-территориальной единицы, в конкретном муниципальном образовании, предопределяется следующими направлениями:

— разработка и реализация программ и планов социально-экономического развития;

— выполнение задач и функций, отнесенных общегосударственным законом к совместному ведению государственных (региональных) и муниципальных органов;

- решение отдельных вопросов, когда взаимная передача полномочий невозможна или не состоялась по различным причинам;

- координация усилий для выполнения задач, имеющих большое значение для населения, проживающего на данной территории (укрепление общественного порядка, социальная помощь, занятость трудовых ресурсов, здравоохранение, экология и охрана природы, выравнивание социально-экономического положения муниципального образования и т. д.);

- обеспечение внутреннего разделения труда и специализация муниципальных образований, налаживание кооперации между субъектами хозяйствования;

Prawo 333, 2021

(C) for this edition by CNS 
— формирование нормативно-правовой базы для решения вопросов местного значения;

- создание совместных государственно-муниципальных организаций.

Указанные направления взаимодействия государственных и муниципальных органов, включенных в единую систему публичной власти, должны обеспечивать развитие территории как единого социально-экономического комплекса.

Проходит время, неумолимо сменяющее поколения людей, общественный строй, политические режимы... Меняются люди, общества, государства. Не стоит на месте наука, пребывая в постоянном поиске новых идей. Работы польского ученого Т. Биго изобилуют добротным анализом правовых актов, критическим взглядом на их научные интерпретации, на основе чего были выдвинуты новые на тот период концептуальные подходы к осуществлению государственного управления и формированию административного права во всем пространстве взаимоотношений с институтами публично-правовых корпораций. Отдавая дань наследию польского ученого Т. Биго, мы с добрыми чувствами отмечаем, что он был сотрудником Вроцлавского университета, с которым наш университет - Всероссийский государственный университет юстиции Министерства юстиции России - связывают сложившиеся дружеские отношения научного сотрудничества. Хочется выразить уверенную надежду на их продолжение. Залогом тому служит преемственность поколений ученых, продолжателей дела административистов славного прошлого, научный задел которых проложил дорогу для изысканий, устремленных в будущее.

\section{Библиография}

Bigo T., Prawo administracyjne. Część ogólna (stenogram wykładów uniwersyteckich), Lwów 1932. Bigo T., Z ustrojowych zagadnień samorząu, Lwów 1933.

Bigo T., Zwiazki publiczno-prawne w świetle ustawodawstwa polskiego, Warszawa 1990.

Panejko J., Geneza i podstawy samorządu europejskiego, Wilno 1934.

\section{Local Government Authorities in the System of Public Authorities: Experiences of Poland and Russia}

Summary

The article deals with several aspects of the organization and activities of local government authorities in the system of public authorities. The basic concepts of local government theories, which influenced the formation of legislation on local government authorities in Poland and Russia, are 
discussed. Polish and Russian practical experiences regarding the legal forms of public law entities in the field of state and municipal administration are presented in a comparative manner, taking into consideration Tadeusz Bigo's scientific views. The article presents the constitutional amendments on the unity of the system of public authorities, introduced into the Russian Constitution recently. On the basis of comparative analogies regarding organization and interactions between the state and municipal levels of public authority in Poland and Russia, the most significant directions and forms of their legal regulation are outlined.

Keywords: public authority, system of public authorities, local government, municipality, local government authorities, theories of local government, legislation. 